\title{
A Test of Positional Properties of Avian Wing-Bud Mesoderm
}

\author{
BRUCE M. CARLSON \\ Departments of Anatomy and Biological Sciences, University of Michigan, Ann Arbor, Michigan 48109
}

\begin{abstract}
Supernumerary wing structures are readily produced by grafting pieces of wing-bud mesoderm into different locations of host wing buds, but the mechanism underlying their formation remains obscure. The major aim of this study was to examine the ability of posterior quail wing-bud mesoderm, cultured in vitro long enough to lose ZPA (zone of polarizing activity) activity, to stimulate or participate in the formation of supernumerary structures when grafted into anterior slits of host chick wing buds. Small pieces of anterior and posterior quail wing-bud mesoderm (HH stages 21-23) were placed in in vitro culture for up to 3 days. After 2 days, ZPA activity of cultured mesoderm was lost. After the grafting of 2- to 3-day cultured anterior quail wing-bud mesoderm into posterior slits of host chick wing-buds, a consistently high percentage (70\%-90\%) of grafts result in formation of supernumerary cartilage; in this experiment, however, only a low percentage of grafts resulted in supernumerary cartilage when 2- to 3-day cultured posterior mesoderm was grafted into anterior slits. Taken with controls, these results show that positional differences exist between cultured anterior and posterior wing-bud mesoderm. Serial-section analysis of numerous operated wings has shown several patterns of contribution to supernumerary structures by cells of graft and host. Single supernumerary digits induced by grafts of ZPA mesoderm into anterior slits were normally composed entirely of host cells, but graft cells regularly contributed to skeletal elements of more complex supernumerary structures. Cartilage rods produced by anterior-to-posterior grafts were composed mostly of graft cells, but cartilage nodules and the bases of some rods were often mosaics of chick and quail cells. The results support the proposition that mesodermal cells of the quail wingbud possess a form of anteroposterior positional memory, but its nature and the means by which the memory of grafted cells interacts with host mesoderm are still not clear.
\end{abstract}

\section{INTRODUCTION}

In recent years, this laboratory has investigated the production of supernumerary structures, mainly rods and nodules of cartilage, produced by grafting small pieces of anterior quail wing-bud mesoderm into posterior slits in host chick wing buds (Carlson, 1984a,b; Stocker and Carlson, 1988). The experimental evidence suggests that this response is related to positional properties of the grafts in relation to those of the host site. Although the nature of the positional properties of avian limb-bud mesoderm remains obscure, there are two schools of thought as to the differing mechanisms that may account for the phenomenon of implant-induced supernumerary structures in this system.

According to one hypothesis, positional specification in the limb bud is dominated by the zone of polarizing activity (ZPA), a region of posterior mesoderm that was found by Saunders and Gasseling (1968) to induce the formation of supernumerary digits after it is grafted into the anterior margin of the limb bud. It has been postulated (Tickle et al., 1975; Summerbell and Tickle, 1977; Summerbell and Honig, 1982) that the cells of the ZPA produce a diffusible morphogen that diffuses along the anteroposterior (A-P) axis of the limb bud and that digital specification occurs in response to the local concentration of the morphogen. The essence of this hypothesis is a response of the mesodermal cells to a long-range morphogenetic signal generated by the ZPA.

The other major hypothesis, based upon the polar coordinate model of morphogenetic control in limb regeneration (French et al., 1976), relies on local cellular interactions as the basis of morphogenetic control. Applied to the developing avian limb, this hypothesis relies heavily on the formation of new cells by intercalation to fill in gaps in a morphogenetic continuum when anterior and posterior tissues are juxtaposed by grafting (Iten, 1982; Javois, 1984).

Both of these hypotheses claim to provide explanations for the formation of supernumerary structures when posterior limb bud tissue is grafted into anterior sites and vice versa. In the avian wing bud the basic phenomenology can be summarized as follows: When fresh posterior mesoderm or mesoderm plus ectoderm is grafted into anterior sites, supernumerary structures, consisting of well-defined digits, as well as unidentifiable cartilaginous elements, are the rule (Summerbell and Honig, 1982). When pieces of fresh anterior mesoderm and ectoderm are grafted into posterior sites, supernumerary structures with recognizable digits form (Iten and Murphy, 1980), but if anterior mesoderm alone is grafted into a posterior site, supernumerary structures consisting of rods and nodules of cartilage, but never digits, form (Fallon and Thoms, 1979; Carlson, 1984a).

The present investigation was directed toward further clarification of the nature of the responses elicited by grafting anterior wing-bud mesoderm into posterior slits in host wing buds or vice versa. To a certain extent, the

Address reprint requests to Dr. Bruce M. Carlson, Department of Anatomy, 4622 Medical Science II Bldg., University of Michigan, Ann Arbor, Mí 48109.

Received September 12, 1986. Accepted December 21, 1987. 
experiments constitute a test of the two hypotheses described above, but it should be recognized that they do not constitute the only possible explanations for the experimental data amassed so far.

Two experiments are reported here. The first was directed toward the relationship between polarizing activity and the formation of implant-induced supernumerary structures. This experiment was stimulated by the possibility that the supernumerary structures arising from the grafting of anterior tissues into posterior slits are the result of a response of the grafts to the polarizing activity of the ZPA of the host wing bud, instead of local interactions between anterior and posterior cells. Since it is not possible to remove polarizing activity from a host wing bud, a different strategy was adopted. Honig (1983) has already shown that the polarizing activity of ZPA mesoderm is lost after 2 days of in vitro culture. The evidence for this assertion is the lack of formation of supernumerary digits after grafting cultured posterior wing mesoderm into anterior sites in the wing bud. Yet when pieces of anterior mesoderm are cultured in vitro and grafted into posterior slits, high percentages of supernumerary cartilage result (Carlson, 1984b).

The essence of this experiment was to culture posterior mesoderm in vitro for a period long enough to lose its polarizing activity, but for a short enough time that, at least with anterior mesoderm, still allows supernumerary cartilage to form after grafting. If a high percentage ( $>80 \%$ ) of grafts produce rods or nodules of supernumerary cartilage after the grafting of cultured posterior mesoderm into anterior slits, then the polarizing activity of the ZPA can be eliminated as a major mechanism in the formation of the supernumerary cartilage. If, on the other hand, supernumerary cartilage does not form, the likelihood is greater that ZPA activity is an important factor in the genesis of the supernumerary structures.

The second part of this investigation consisted of determining the cellular contributions by graft and host to implant-induced supernumerary limb formation in avian limb buds. Individual examples of such determinations have been published (Iten, 1982; Summerbell and Honig, 1982), but these have been presented as examples designed to bolster a particular viewpoint, rather than as a complete series. In this investigation the results of all examples of experimental series are presented with the aim of providing the spectrum of the cellular responses to a particular experimental manipulation.

\section{MATERIALS AND METHODS Experimental Animals}

In all cases, graft material came from embryos of Japanese quail (Coturnix coturnix japonica) from a colony maintained at the University of Michigan. Hosts were embryos of white Leghorn chickens (Gallus domesticus), obtained from David Bilbie, Ann Arbor, MI. The eggs of both species were maintained at $37.5^{\circ} \mathrm{C}$ in a humidified forced-air incubator before and after the operations. Both chick and quail embryos were staged according to Hamburger and Hamilton (1951). Host and donor embryos ranged from stages 21 to 23 .

\section{In Vivo Operations}

Donor tissue from host quail embryos was obtained by removing wedges of mesoderm and ectoderm, 150-200 $\mu \mathrm{m}$ on each side, from the anterior border (level of the



Fig. 1. Chick wing with duplicated second and third digits $(2,3)$ and a more proximal sliver of supernumerary cartilage (arrow), resulting from the implantation of fresh posterior quail wing mesoderm into an anterior slit of host chick wing bud. The white outline indicates the distribution of quail cells, as determined by serial section analysis. Combined Feulgen-Victoria blue B stain.

junction of somites $16-17$ ) or the ZPA region on the posterior border of the wing bud. For identification of the ZPA region, the maps of MacCabe et al. (1973) were used as a guide.

In most experiments, the ectoderm was removed from the wedges by incubating them for $10 \mathrm{~min}$ in a $2 \%$ trypsin-pancreatin solution (Gibco, Grand Island, NY) at $4^{\circ} \mathrm{C}$. After three rinses in Hanks' balanced salt solution (Gibco), the ectoderm had separated from the mesoderm and could be easily picked off from the mesoderm.

Grafted tissues, whether cultured or fresh, were placed into slits made in the posterior or anterior border of the host chick wing bud. All grafts, whether fresh or cultured mesoderm, were cut to approximately the same size (about $100 \times 200 \mu \mathrm{m}$ ) in preparation for grafting. Anterior-to-posterior grafts were made exactly as in previous experiments (Carlson, 1984a,b). Posterior-to-anterior grafts were placed into slits made in locations similar to those from which anterior wedges were removed. It should be noted that the host embryos were older than those commonly used in ZPA-grafting experiments (e.g., Honig and Summerbell, 1985). This was done for consistency with previous experiments involving anterior-to-posterior grafts done in this laboratory.

\section{In Vitro Culture}

Pieces of posterior mesoderm were pipetted onto small pieces of $0.6-\mu \mathrm{m}$ pore-size Nuclepore filters that were supported at the medium-air interface by fine-mesh 
stainless-steel screen platforms. Each platform was placed in a $35-\mathrm{mm}$ plastic culture dish. The medium consisted of BME (diploid) containing Earle's salts and added glutamine, $10 \%$ horse serum, and $5 \%$ chick embryo extract (all from Gibco). Penicillin (10\% IU/ml) and streptomycin $(50 \mu \mathrm{g} / \mathrm{ml})$ were added to the medium. The tissues were cultured at $37^{\circ} \mathrm{C}$ in a highly humidified incubator and exposed to an atmosphere of $5 \%$ carbon dioxide and $95 \%$ air. At the end of the culture period, the tissues were mechanically removed from the filters with a tungsten needle and placed into Hanks' solution while awaiting grafting. The cultured tissues were lightly stained with Nile blue sulfate to improve their visibility during and after grafting.

\section{Morphological Procedures}

After the implantation operations, the host embryos were allowed to develop for 8 additional days. The embryos were then removed, and the wings were fixed overnight in a fresh 17:2:1 mixture of ethanol, formalin, and glacial acetic acid. They were then stained en bloc with the Feulgen stain. Subsequently, the cartilage was stained by the Victoria B blue technique (Carlson et al., 1985). The doubly stained wings were first analyzed for supernumerary skeletal elements. Gross specimens to be analyzed histologically were photographed. They were then embedded in paraffin, serially sectioned at $7 \mu \mathrm{m}$, and counterstained with fast green.

Due to the nuclear marker on the quail cells (LeDouarin, 1973), the distribution of quail and chick cells could be readily determined on the sections. Because the shape of the normal and supernumerary skeletal structures was obvious on the gross photographs of the wings, it was possible to map the distribution of grafted quail cells in the wings without having to resort to laborious reconstruction techniques.

The combination gross-skeletal/Feulgen staining technique was used in two different ways. In one series, 13 consecutive wings with supernumerary structures resulting from standard anterior-to-posterior grafts of fresh quail mesoderm were analyzed, regardless of the outcome of the operation. In a comparison series, 22 wings with supernumerary structures resulting from standard posterior-to-anterior grafts of fresh quail mesoderm were similarly analyzed. Selected wings bearing posterior-toanterior grafts of 1- to 3-day cultured quail mesoderm were also sectioned serially in order to analyze the contribution of graft and host cells to specific types of supernumerary structures. Fifty-eight of these wings were subjected to this form of analysis.

\section{Statistical Tests}

Statistical tests of significance between groups were done according to the chi-square "fourfold" table (Hill, 1966).

\section{RESULTS}

\section{Culture of ZPA Tissue}

The initial experiment consisted of culturing ZPA mesoderm from stage 21-22 quail donor embryos and grafting the cultured mesoderm into standard anterior slits of host chick wing buds. Analysis consisted of determining the percentage of wings bearing identifiable supernumerary digits and/or nodules or rods of supernumerary cartilage (Fig. 1). As can be seen from
Table 1 and Figure 2, the ability of grafts of in vitro cultured ZPA mesoderm to stimulate the formation of supernumerary digits declined dramatically over the first 2 days in culture and had disappeared entirely by the third day in culture. Not only did the percentage of induced supernumerary digital structures decline, but their complexity declined as well. Anterior-to-anterior control implants produced no supernumerary digits.

The percentage of nodules or rods of non-digital supernumerary cartilage was low $(<20 \%)$ from the beginning in grafts of both fresh and cultured polarizing zone mesoderm (Table 1, Fig. 3). At no time was the percentage of supernumerary non-digital cartilage in experimental wings significantly higher than in controls.

\section{Histological Study}

Although there was considerable variation in both the gross response to grafting and the cellular composition of the host wings and resulting supernumerary structures, certain patterns were, nevertheless, identifiable. The histological observations on these wings, which had also been stained for gross cartilage, are described below.

\section{Fresh Anterior-to-Posterior Grafts}

Of the 13 wings in this series, 12 contained rods or nodules of supernumerary cartilage. Seven of these limbs contained cartilaginous rods that were composed entirely of quail cells (Fig. 4). In one additional rod, the posterior base consisted of chick cells. Three of the four discrete cartilaginous nodules were clear mosaics, containing roughly 50\% chick cells (Fig. 5 ). The other nodule was formed entirely of chick cells.

Outside the supernumerary cartilage, the quail cells were morphologically well integrated into normal chick anatomical structures. In nine wings, quail cells were integrated into the normal skeleton, usually in proximal areas of the ulna or the region of the lateral epicondyle of the humerus. More often than not, a thin row of quail cells extended along the subepidermal region along the proximolateral ulna. Another common distribution of quail cells was in the periosteum of the olecranon process and proximal ulna. In several wings, a band of quail cells arising from a supernumerary cartilaginous rod at the elbow comprised the proximal tendon of the flexor digitorum superficialis muscle. In both the soft tissues and skeletal structures, the boundaries between quail and chick cells were quite distinct. The intermingling of more than a few chick and quail cells at boundary regions was never seen in this series.

\section{Fresh Posterior-to-Anterior Grafts}

The 22 grafts of fresh posterior (ZPA) wing mesoderm into anterior slits produced a variety of types of supernumerary structures, ranging from protuberances of cartilage off the normal skeleton to complex duplications of autopodial and stylopodial parts. Although there was considerable variation, several clear-cut patterns of chick-quail cellular distribution became apparent.

Supernumerary digits were subdivided into simple structures (single digits and metacarpal elements, sometimes hypomorphic) and complex structures (more than one digit or metacarpal and, occasionally, duplication of the radius). Quail cells were never found in the supernumerary skeletal elements of single digits (11 cases). Most commonly, they were located in the antecubital area, being integrated into both the normal skeleton 
TABLE 1. Total numbers of grafts (and percentages) showing various responses to the implantation of cultured quail mesoderm into anterior and posterior slits of chick wing buds

\begin{tabular}{|c|c|c|c|c|c|c|}
\hline Group & $\begin{array}{l}\text { SN digits } \\
\text { only }\end{array}$ & $\begin{array}{c}\text { SN } \\
\text { cartilage } \\
\text { only }\end{array}$ & $\begin{array}{l}\text { SN digits } \\
\text { plus SN } \\
\text { cartilage }\end{array}$ & Normal & $\begin{array}{l}\text { Bent } \\
\text { humerus }\end{array}$ & $\begin{array}{l}\text { Other } \\
\text { anomaly }\end{array}$ \\
\hline \multicolumn{7}{|c|}{$\begin{array}{l}\text { ZPA (posterior) mesoderm } \\
\text { into anterior slit }\end{array}$} \\
\hline $\begin{array}{l}0 \text { Day (fresh) } \\
\text { mesoderm }\end{array}$ & $14(93.3)$ & 0 & $1(6.7)$ & 0 & 0 & 0 \\
\hline 1-Day cultured & $10(29.4)$ & $4(11.8)$ & 0 & $19(55.9)$ & 0 & $1(2.9)$ \\
\hline 2-Day cultured & $3(7.9)$ & $3(7.9)$ & $3(7.9)$ & $15(39.5)$ & $10(26.3)$ & $4(10.5)$ \\
\hline 3-Day cultured & 0 & $5(18.5)$ & & $17(63.0)$ & $3(11.1)$ & $2(7.4)$ \\
\hline 4-Day cultured & 0 & $1(5.0)$ & 0 & $15(75.0)$ & $4(20.0)$ & \\
\hline \multicolumn{7}{|c|}{$\begin{array}{l}\text { Anterior mesoderm into } \\
\text { anterior slit }\end{array}$} \\
\hline $\begin{array}{l}0 \text { Day (fresh) } \\
\text { mesoderm }\end{array}$ & 0 & $1(5.0)$ & 0 & $19(95.0)$ & 0 & 0 \\
\hline 1-Day cultured & 0 & $1(3.8)$ & 0 & $21(80.8)$ & 0 & $4(15.4)$ \\
\hline 2-Day cultured & 0 & $1(4.2)$ & 0 & $14(58.3)$ & 0 & $9(37.5)$ \\
\hline 3-Day cultured & 0 & $1(9.1)$ & 0 & $7(63.6)$ & $1(9.1)$ & $2(18.2)$ \\
\hline \multicolumn{7}{|c|}{$\begin{array}{l}\text { Posterior mesoderm into } \\
\text { posterior slit }\end{array}$} \\
\hline $\begin{array}{l}0 \text { Day (fresh) } \\
\text { mesoderm }\end{array}$ & & 0 & 0 & $21(100)$ & 0 & 0 \\
\hline 1-Day cultured & 0 & $3(11.5)$ & 0 & $20(76.9)$ & $1(3.8)$ & $2(7.6)$ \\
\hline 2-Day cultured & 0 & $2(22.2)$ & 0 & $6(66.7)$ & & $1(11.1)$ \\
\hline 3-Day cultured & 0 & $2(6.9)$ & 0 & $18(62.1)$ & $2(6.9)$ & $7(24.1)$ \\
\hline \multicolumn{7}{|c|}{$\begin{array}{l}\text { Anterior mesoderm into } \\
\text { posterior slit }\end{array}$} \\
\hline $\begin{array}{l}0 \text { Day (fresh) } \\
\text { mesoderm }\end{array}$ & 0 & $50(92.6)$ & 0 & $1(1.9)$ & $2(3.8)$ & $1(1.9)$ \\
\hline 1-Day cultured & 0 & $39(83.0)$ & 0 & $6(12.8)$ & $2(4.3)$ & 0 \\
\hline 2-Day cultured & 0 & $31(81.6)$ & 0 & $2(5.3)$ & $5(13.2)$ & 0 \\
\hline 3-Day cultured & 0 & $18(66.7)$ & 0 & $8(29.6)$ & $1(3.7)$ & 0 \\
\hline 4-Day cultured & 0 & $15(78.9)$ & 0 & $2(10.5)$ & $2(10.5)$ & 0 \\
\hline
\end{tabular}

${ }^{1}$ Data from Carlson (1984b).

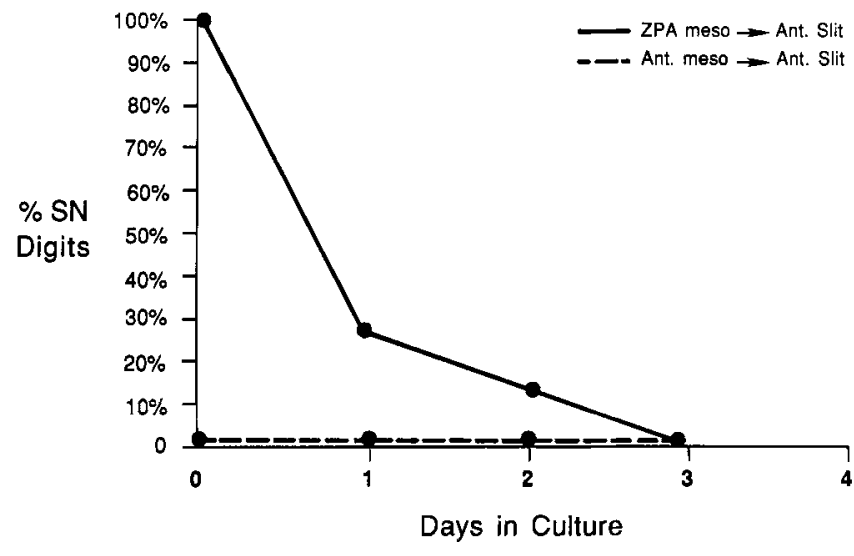

Fig. 2. Graph showing the decline in the ability of cultured quail wing mesoderm to stimulate the formulation of supernumerary (SN) digits when implanted into anterior slits of host chick wing buds. ZPA meso. = posterior mesoderm placed into culture and grafted into the host wing bud. Ant. meso. = anterior mesoderm placed into culture and grafted into the host wing bud.



Fig. 3. Graph showing the percentages of non-digitiform supernumerary cartilage formed after grafting cultured quail wing mesoderm into anterior slits of host chick wing buds. None of the points of this graph differ significantly $(P=.05)$ from the others at any time point. Abbreviations used are the same as in Figure 2. 

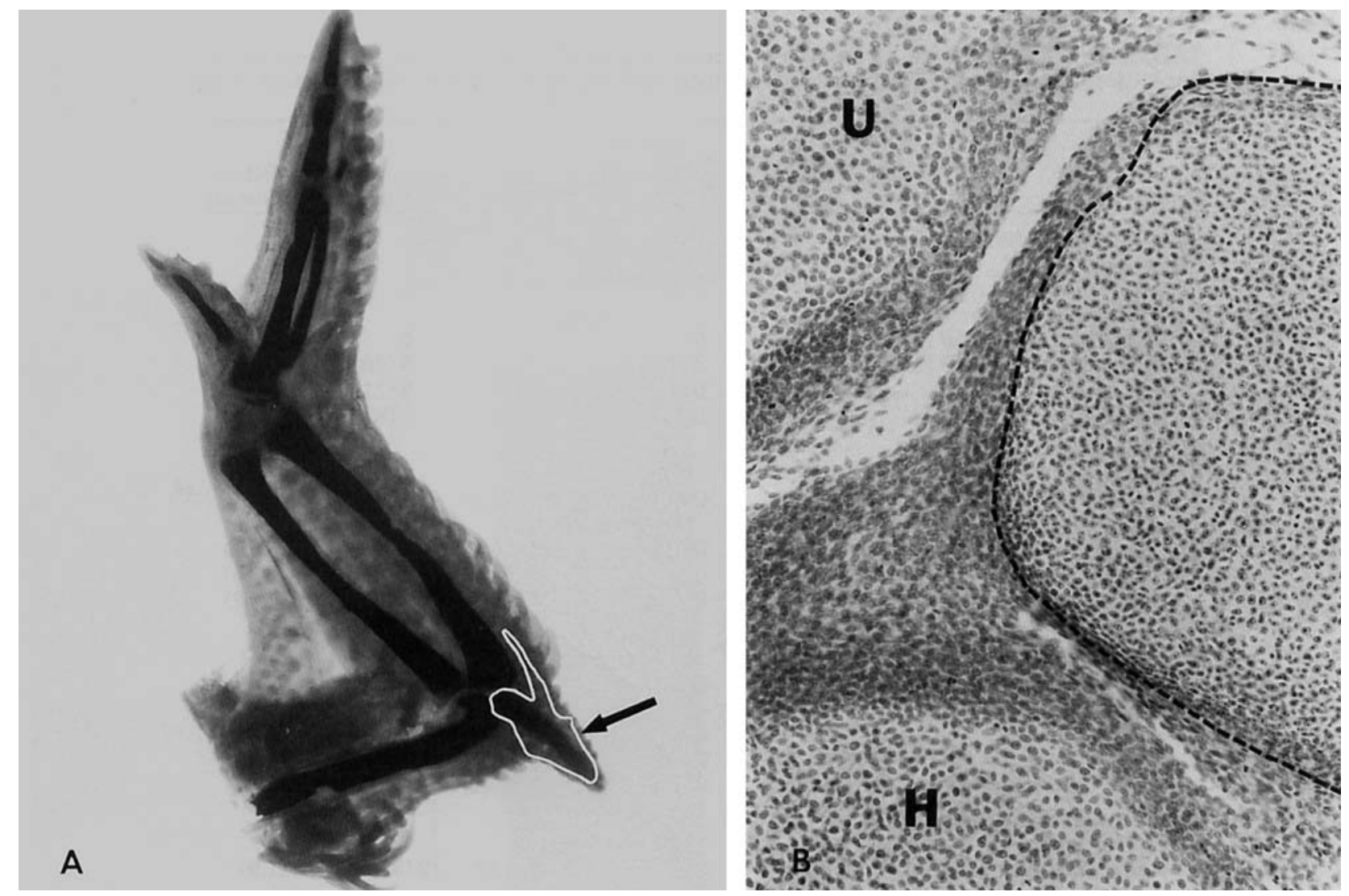

Fig. 4. A: Typical supernumerary cartilaginous rod (arrow) formed after the implantation of fresh anterior quail wing bud mesoderm into a posterior slit in a host chick wing bud. The location of quail cells is outlined in white. Combined Feulgen-Victoria blue B stain. B: Histo-

logical preparation of the base of the supernumerary rod indicated at left. The quail cells at the base of the rod are outlined by the black dashed line. $\mathrm{H}=$ humerus; $\mathrm{U}=$ ulna. $\times 223$.

(distal humerus and/or proximal radius) and soft tissues, including the web (Fig. 6).

The more complex the supernumerary structures, the greater the likelihood that quail cells would be found in supernumerary skeletal elements. In this series, quail cells were found in skeletal structures in six of nine complex supernumeraries. In five of the six positive cases, an entire metacarpal and most of the proximal phalangeal cartilage were of quail origin (Figs. 7,8 ).

Four of the wings in this series possessed nodules or protuberances of supernumerary cartilage in addition to supernumerary digits; two wings not bearing supernumerary digits also contained such structures. With one exception (Fig. 9), these structures were formed entirely of quail cells (Figs. 1, 10).

\section{Grafts of Cultured Posterior Tissues Into Anterior Slits}

Although the wings in this series were selected for histology on the basis of their gross skeletal structure, rather than sequentially, as was the case for the fresh grafts, the patterns of cellular composition of these hybrid wings were similar to those noted above.

Of the limbs containing grafts of cultured mesoderm only, the 11 single or hypomorphic supernumerary dig- its contained no quail cells in the skeletal elements or the soft tissues immediately surrounding them. The single complex supernumerary structure contained quail cells in the soft tissues along the length of a supernumerary digit, but not in the cartilage. Slides of nine wings with non-digital supernumerary cartilaginous elements were examined. All were composed of quail cells, with no chick cells included.

One general tendency was noted in the culture experiments. The longer the period of culture, the less the implanted quail cells spread out among the tissues of the host wing. In tissues cultured for 2 days, the implanted cells tended to remain within the soft tissues of the limb and to not become integrated with the normal skeleton. Of 11 limbs bearing 2-day cultured ZPA grafts, only one had any quail cells in the normal skeleton.

\section{DISCUSSION}

The results of the present investigation, along with previously published reports on mesodermal grafting in wing buds, reveal a set of complex responses. Some of these responses correspond to predictions that can be inferred from existing morphogenetic models; others do not. The results of the present investigation and those 

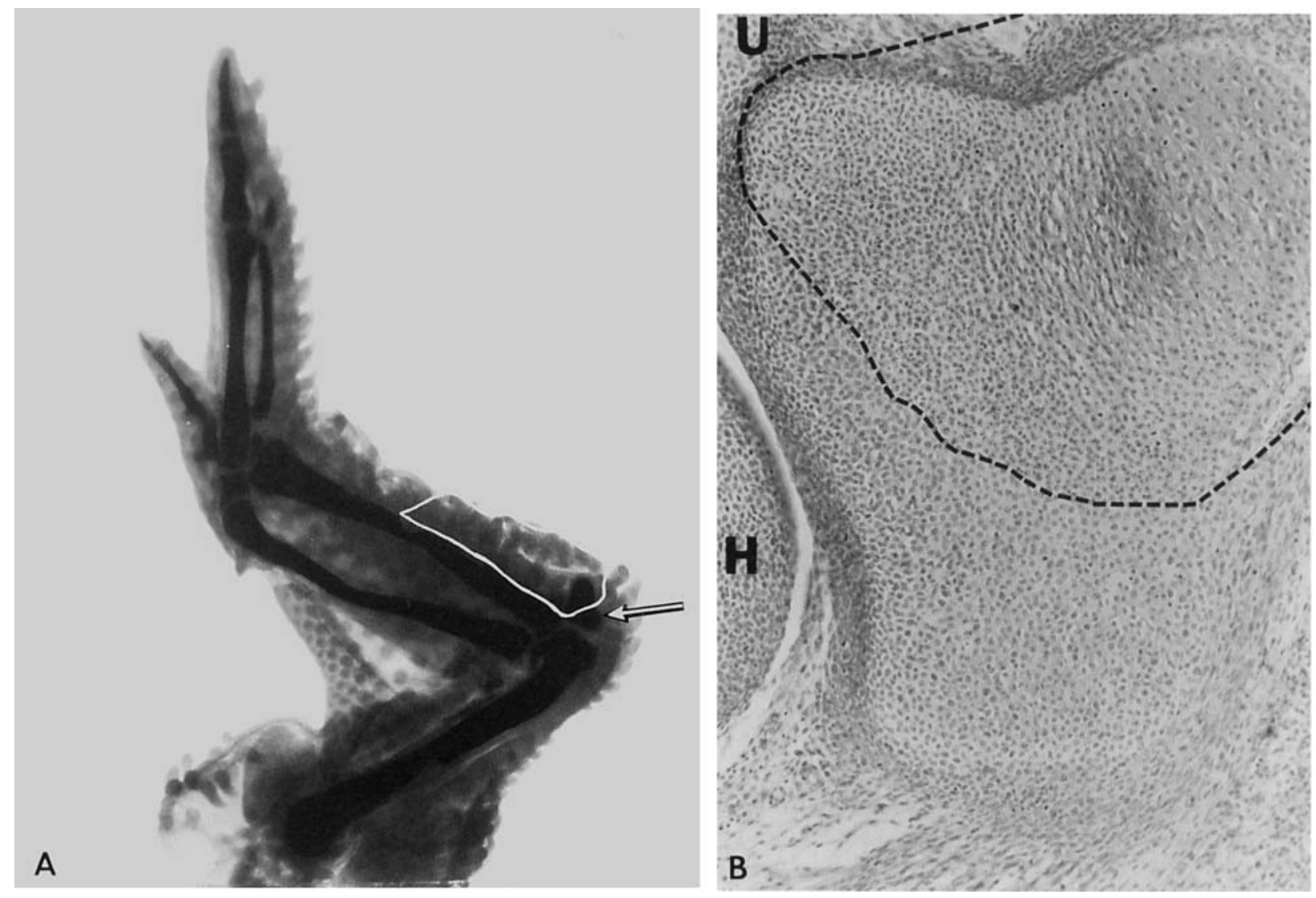

Fig. 5. A: Typical supernumerary cartilaginous nodule (arrow) formed after the implantation of fresh anterior quail wing bud mesoderm into a posterior slit in a host chick wing bud. The location of quail cells is outlined in white. Combined Feulgen-Victoria blue B stain. B: Histo- logical preparation of the base of the supernumerary cartilaginous nodule seen at left. The quail cells are outlined by the black dashed line. $\mathrm{H}=$ humerus; $\mathrm{U}=$ ulna. $\times 166$. of other experiments from this laboratory will be treated together in this discussion. These results clearly show that there are significant differences in the properties of pieces of anterior and posterior mesoderm used as grafts and also in the anterior and posterior regions of the host wing buds used as implant sites for the grafts.

That there are differences in the grafted quail mesoderm is revealed by their reactions when placed into the same site in host chick wing buds. Fresh anterior mesoderm alone grafted into posterior slits produces supernumerary cartilage in up to $100 \%$ of cases, depending upon the stage of the graft (HH-22 gives the highest percentage; Carlson, 1984a). In contrast, pieces of posterior mesoderm grafted into identical posterior slits form no supernumerary structures (Table 1 ). If similar procedures are done with pieces of fresh mesoderm plus ectoderm, a high percentage of supernumerary digits forms after anterior-to-posterior grafting, whereas posterior-toposterior controls are negative (Iten and Murphy, 1980; Carlson, 1984a). The results of grafting cultured (for up to 4 days) anterior or posterior mesoderm into posterior slits are very similar to those of grafting fresh mesoderm except that after longer-term cultures up to $20 \%$ of posterior-to-posterior grafts produce small cartilaginous nodules. These results all show major differences between anterior and posterior mesodermal grafts; I interpret them to reflect positional properties.

Results of posterior-to-anterior grafting experiments also reveal differences between anterior and posterior mesodermal grafts; grafts of both fresh posterior mesoderm and mesoderm plus ectoderm into anterior sites result in the formation of supernumerary digits, whereas grafts of fresh anterior mesoderm into anterior slits produce only 5\% supernumerary cartilage (Carlson, 1984a). After in vitro culture, grafts of posterior mesoderm lose their ability to stimulate the formation of supernumerary digits (Honig, 1983; and this study); and after 2 days in culture, when polarizing activity (as defined by the ability to induce supernumerary limb formation) is lost, such grafts are also unable to produce greater than control levels of supernumerary rods or nodules of cartilage.

When all of the above data are viewed together, there is no doubt that there are distinct differences between grafts of anterior and posterior wing-bud mesoderm because of their different reactions after being implanted into the same sites. Similarly, the greatly different reactions to grafting identical pieces of anterior or poste- 


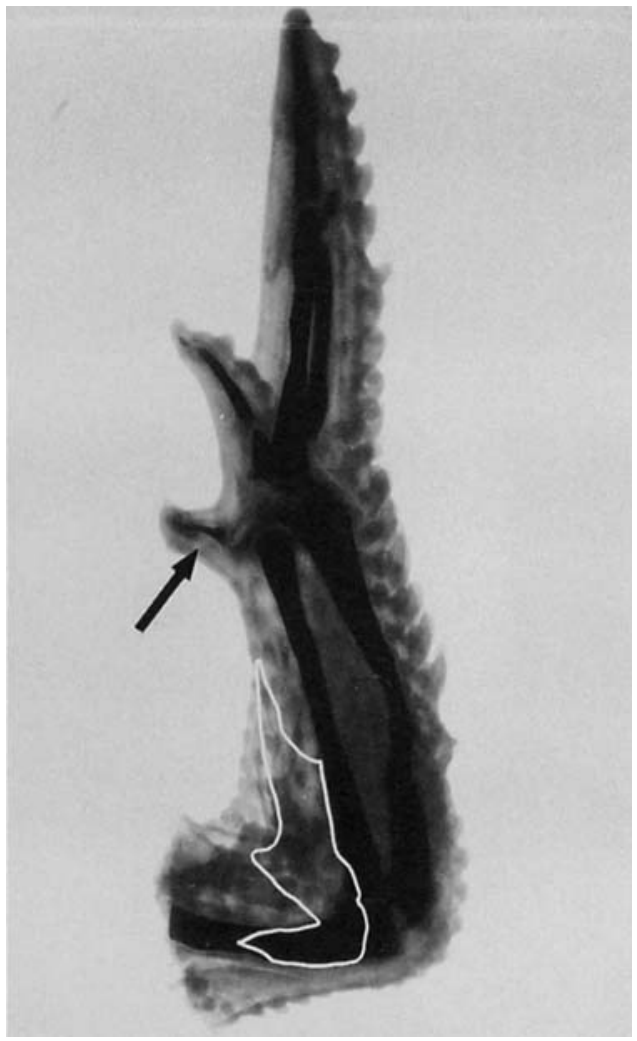

Fig. 6. Chick wing with a hypomorphic supernumerary digit (arrow) resulting from grafting a wedge of fresh posterior quail wing mesoderm into an anterior slit in a host chick wing bud. Quail cells are distributed (white outline) in a segment of the normal humerus, a sliver of the proximal radius, and soft tissues of the wing. FeulgenVictoria blue B stain.

rior mesoderm to different host sites show that there are also great differences between anterior and posterior implant sites in host wing buds.

The in vitro culture experiments also reveal significant differences between anterior and posterior mesoderm. Although high percentages of supernumerary cartilaginous rods and nodules form after the grafting of anterior mesoderm cultured for up to 4 days into posterior slits, after 2 days in vitro cultured posterior mesoderm loses the ability to stimulate supernumerary digits when grafted into anterior slits. With such $(>2$ days in culture) grafts, higher than control levels of non-digitform supernumerary cartilage are never produced.

Enough data have now been accumulated to allow some interpretation of the mechanisms underlying the responses to mesodermal grafting in the avian wing bud. The morphology and complexity of the supernumerary structures resulting from the grafting of anterior mesoderm is significantly different from that following the grafting of posterior mesoderm. Supernumerary digits regularly form after posterior mesoderm alone is grafted into the anterior margin of the wing bud (Summerbell and Tickle, 1977), yet supernumerary digits never form after grafting anterior mesoderm alone into posterior sites (Carlson, 1984a). In contrast, wedge grafts of anterior mesoderm plus ectoderm into posterior sites do form digits (Iten and Murphy, 1980; Carlson, 1984a). The fact that non-digitform supernumerary cartilage forms in anterior-to-posterior grafts of fresh mesoderm is attributed to the absence of the growth-stimulating effect of the overlying ectoderm, because an apical ectodermal ridge does not form in the ectoderm that heals over the graft (Stocker and Carlson, 1988).

The results of the histological study reported here are important in interpreting the grafting experiments. In the series of posterior-to-anterior grafts, all single supernumerary digits were composed only of host cells; most components of more complex supernumerary structures were also of host origin. In contrast, the rods of supernumerary cartilage formed from anterior-to-posterior grafting were composed almost entirely of graft cells. The cellular composition of the graft-induced supernumerary structures strongly suggests that in posterior-toanterior mesodermal grafts the graft acts on the host and that in anterior-to-posterior grafts the host acts on the grafts. The minority of cases in both types of grafts, in which supernumerary structures were mosaics of graft and host cells, do not allow one to rule out entirely the possibility of mutual interaction between graft and host.

The tentative conclusion from the above data is that the supernumerary structures resulting from the juxtaposition of anterior and posterior cells are caused by some influence from the posterior mesoderm (polarizing region) upon anterior mesoderm. This led to the experimental strategy of attempting to produce supernumerary structures by combining anterior and posterior mesoderm in the absence of polarizing activity. The only currently available way to accomplish this was to subject posterior mesoderm to short-term culture so that its classic polarizing activity (the ability to stimulate supernumerary digit formation) is lost (Honig, 1983). The key feature of this experiment was that after 2 to 3 days in

Figs. 7-10. Supernumerary structures resulting from the grafting of wedges of fresh posterior quail mesoderm into an anterior slit in a host chick wing bud. The distribution of quail cells is outlined in white.

Fig. 7. Chick wing with a 4,3 , II, III, IV duplication. Note that a cartilaginous protuberance from the humerus, the lateral two-thirds of the radius, and the skeleton of the supernumerary digit 4 are made of quail cells. Feulgen-Victoria blue B stain.

Fig. 8. A complex set of supernumerary structures. The area of quail cells includes the medial portions of the partially duplicated radius and a hypomorphic supernumerary metacarpal 4 element. FeulgenVictoria blue $B$ stain.

Fig. 9. Chick wing with an unidentified supernumerary cartilaginous element, possibly a hypomorphic radial duplication (arrow). In this case, the supernumerary cartilage is entirely chick, with a smal region of quail cells alongside and at its base. This was the only example of this type of structure found in these experiments. FeulgenVictoria blue B stain.

Fig. 10. Chick wing with a small protuberance of supernumerary cartilage from the mid-humerus. The entire supernumerary cartilage plus the surrounding tissue was composed of quail cells. FeulgenVictoria blue B stain. 

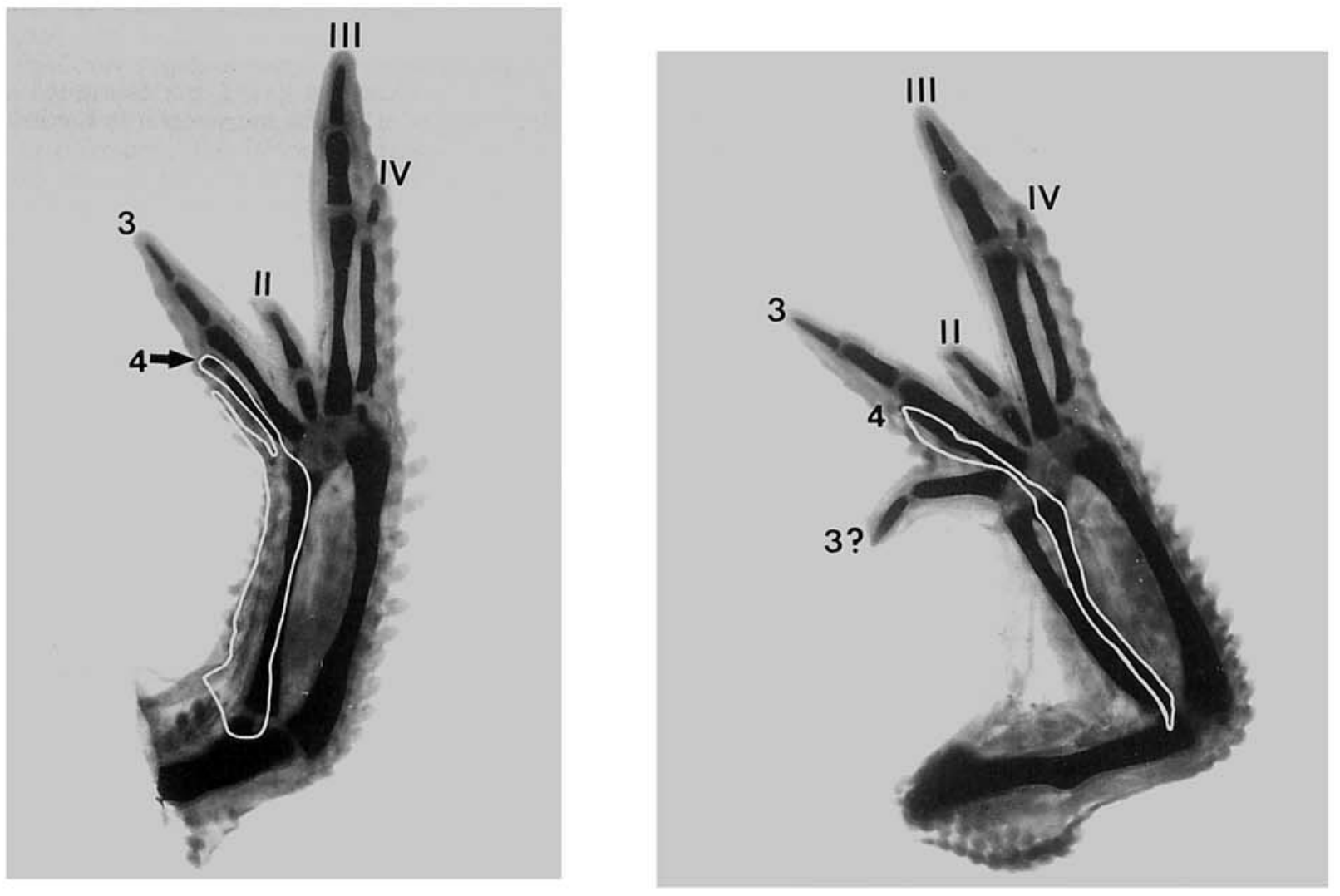

7

8
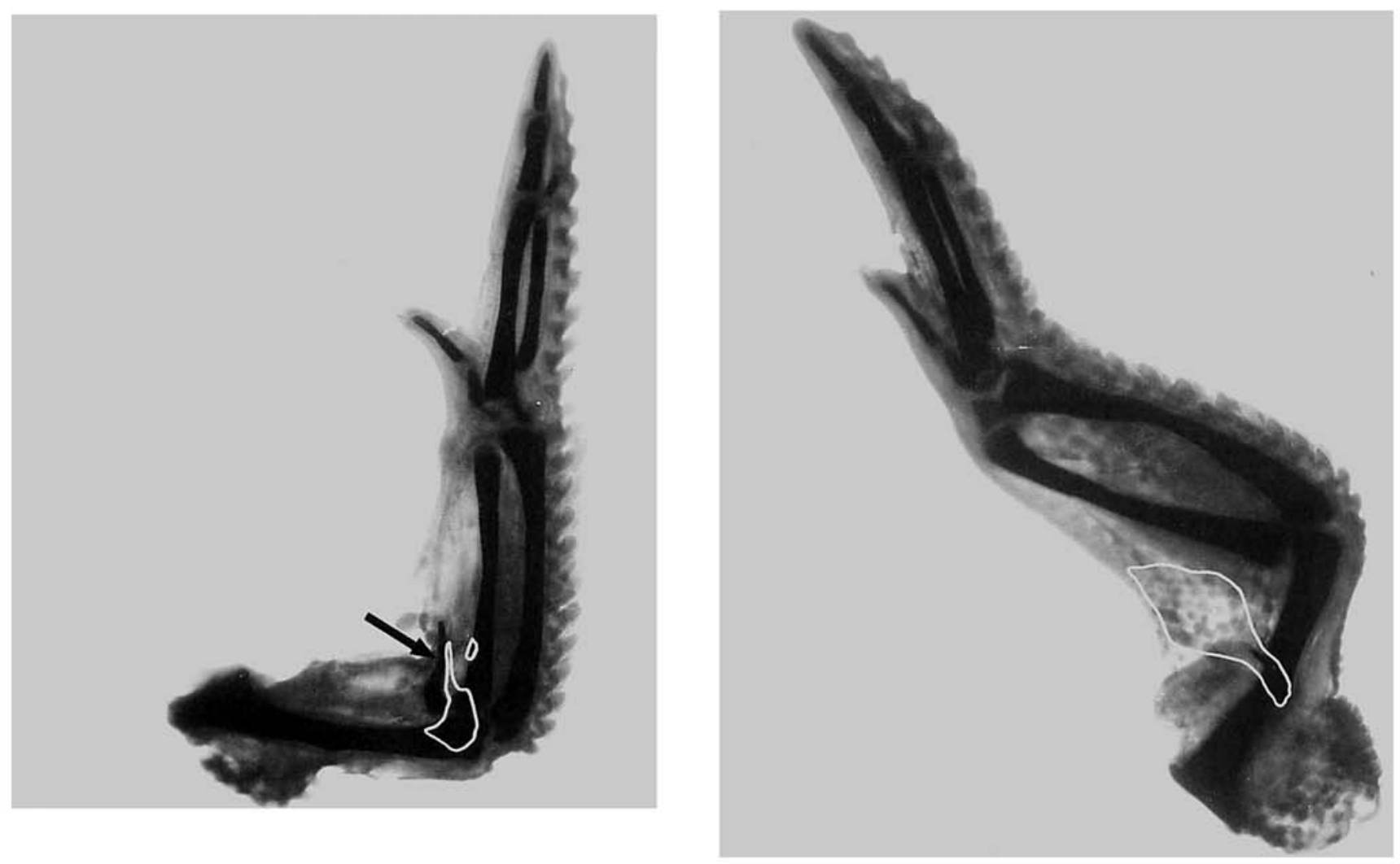
culture, when polarizing activity is lost from posterior mesoderm, anterior mesoderm is still fully capable of forming high percentages of supernumerary structures after grafting into posterior slits. This experiment clearly showed that in the absence of polarizing activity, no supernumerary cartilaginous structures (including rods or nodules) above control levels were formed. This result argues against purely local interactions between anterior and posterior mesoderm without associated polarizing activity as being responsible for the formation of graft-induced supernumeraries, unless one postulates that the properties of posterior cells that participate in the interaction are more labile in culture than those of anterior mesodermal cells. However, local cellular interactions cannot be excluded as mediators of possible long range signals. The sum of all the experiments from our laboratory is that supernumerary cartilage or digits do not form unless active posterior (polarizing) mesoderm is closely apposed to anterior mesoderm. Recently, Dvorak and Fallon (1987) have presented evidence that in the absence of additional tissue, displacement of the polarizing zone in relation to anterior tissue is required for the formation of supernumerary digits.

Although the evidence to date favors an effect of the host ZPA on an anterior-to-posterior mesodermal graft as the main stimulus for the formation of supernumerary cartilage, the fact that some of the cartilaginous nodules were mosaics of graft and host tissue does not allow one to dismiss entirely the possibility of local interactions in the genesis of the supernumerary cartilages. It is important to recognize, however, that the range of graft and host cellular contributions to supernumerary structures resulting from both anterior-toposterior and posterior-to-anterior grafts is so great that one could find individual cases to support any theoretical explanation proposed thus far. These histological findings point out the complexity of the total response to grafting procedures.

The current series of experiments provides evidence in favor of some form of positional memory in mesodermal tissues of the wing bud. The strongest evidence supporting this proposition involves the grafting of cultured mesoderm; the evidence to date suggests some form of interaction between the cells of the graft and the ZPA of the host.

A hypothesis that could be related to suggestions put forth by Smith (1979), Summerbell (1979), and Summerbell and Honig (1982) involves an interaction between cells with different anterior-posterior positional memories and the ZPA. At some time early in wing-bud development the mesodermal cells become imprinted with anterior-posterior positional differences that leave the anterior cells responsive to the influence of the ZPA and the posterior cells non-responsive. The initial positional differences could have been established as a result of exposure to a gradient of ZPA morphogen (Wolpert, 1971; Summerbell and Tickle, 1977; Summerbell, 1979), but this is not necessary.

That the original anteroposterior specifications represent a form of memory is suggested by the fact that anterior mesoderm, cultured for up to 4 days, still responds to grafting into anterior or posterior sites like fresh anterior mesoderm (Carlson, 1984b). Cultured posterior tissue loses its ZPA activity (Honig, 1983; and this study), but this has not been assumed to represent a form of positional memory. However, when up to 4-day cultured posterior mesoderm is grafted into posterior slits, high percentages of supernumerary cartilage still do not form. If it were postulated that continued exposure to high levels of a ZPA morphogen is required to maintain the "posterior" positional properties of this mesoderm, we would expect that, after several days in culture, the conditioning effect of the ZPA would wear off and the grafts of cultured posterior mesoderm into posterior slits would behave more like anterior mesoderm, with the result that they also would form high percentages of supernumerary cartilage when exposed to the influence of the ZPA of the host.

The results of Saunders and Gasseling (1963), who found duplications after temporary reversal of wing-bud apices, also support a form of "memory" or specification of wing-bud mesoderm after the cessation of exposure to the influence of polarizing zone, although it could be argued that the polarizing zone cells migrated into the anterior part of the apex before re-rotation. The results suggest a longer-term anteroposterior memory than that proposed by Summerbell (1979) on the basis of filterimposition experiments.

Our experiments to date suggest the following properties of an anteroposterior positional memory in avian wing mesoderm:

1. Positionally related differences along the anteroposterior axis exist in fresh quail mesoderm (Carlson, 1984a).

2. The expression of these differences falls off sharply with age, starting with $\mathrm{HH}$ stage 25 (Carlson, 1984a).

3 . The positional memory does not require continuous input from the developing limb field, since it is preserved in pieces of intact mesoderm cultured in vitro for up to 4 days (Carlson, 1984b).

4. The positional memory is a function of the individual cells of the mesoderm, rather than depending upon the integrity of the mesoderm of a given region. This was demonstrated by the ability of freshly dissociated mesodermal cells to respond to different graft sites in the same way as do blocks of intact mesoderm (Stocker and Carlson, 1988).

5 . The extracellular matrix per se is not the repository for the positional memory analyzed here, for after enzymatic digestion of the matrix, the position properties of the cells are retained (Stocker and Carlson, 1988). It is still possible that a positional memory in or on mesodermal cells is mediated by secreted matrix materials.

6. Mesodermal cells do not need to be in constant contact with each other via gap functions or other mechanisms to retain their positional properties (Stocker and Carlson, 1988).

7. In the absence of functional ZPA activity, an interactive positional effect has not been demonstrated in posterior mesoderm.

8. Local interactions between positionally disparate mesoderm cannot be excluded on the basis of studies of cellular contributions to supernumerary structures.

9. Virtually nothing is yet known about the nature of the positional memory in question.

It is now apparent that the anteroposterior positional memory of the avian wing bud differs in many fundamental respects from the long-term positional memory 
inherent in muscle and dermis of the urodele amphibian limb (Carlson, 1975, 1983). Two major differences are the lack of response to grafting in older avian embryos (Carlson, 1984a) and the qualitative difference in response to anterior-to-posterior vs. posterior-to-anterior grafting in the limb. In amphibians, supernumerary digits form after grafting of mesoderm (muscle or dermis) into both anterior and posterior sites. At this point, the major similarity is our lack of knowlege of the concrete basis for positional memory in either system.

\section{ACKNOWLEDGMENTS}

Supported by NIH grant HD-17228. I wish to thank Jean Carlson and Cindy Fabricius-Segal for technical assistance and John Beckerman for photography.

\section{LITERATURE CITED}

Carlson, B.M. 1975 The effects of rotation and positional change of stump tissues upon morphogenesis of the regenerating axolotl limb. Dev. Biol., 47:269-291.

Carlson, B.M. 1983 Positional memory in vertebrate limb development and regeneration. In: Limb Development and Regeneration. J.F. Fallon and A.I. Caplan, eds. Alan R. Liss, New York, Pt. A, pp 433-443.

Carlson, B.M. 1984a The formation of supernumerary structures after grafting anterior quail wing bud mesoderm of various ages into chick wing buds. Dev. Biol., 101:97-105.

Carlson, B.M. 1984b The preservation of the ability of cultured quail wing bud mesoderm to elicit a position-related differentiative response. Dev. Biol., 101:106-115.

Carlson, B.M., S.K. Simandl, K.M. Stocker, T.G. Connelly, and J.F. Falion 1985 A method for the combined gross skeletal staining and Feulgen staining of embryonic chick tissues. Stain Technol., 61:2731.

Dvorak, L., and J.F. Fallon 1987 The ability of the chick wing bud to regulate positional disparity along the anterior-posterior axis. Dev. Biol., 120:392-398.

Fallon J.F. and S.D. Thoms 1979 A test of the polar coordinate model in the chick wing bud. Anat. Rec., 193:534.

French, V., P.J. Bryant, and S.V. Bryant 1976 Pattern regulation in epimorphic fields. Science, 193:696-981.

Hamburger, V., and H.L. Hamilton 1951 A series of normal stages in the development of the chick embryo. J. Morphol., 88:49-67.

Hill, A.B. 1966 Principles of Medical Statistics. Oxford University Press, New York.
Honig, L.S. 1983 Polarizing activity of the avian limb examined on a cellular basis. In: Limb Development and Regeneration. J.F. Fallon and A.I. Caplan, eds. Alan R. Liss, New York, Pt. A, pp. 99-108.

Honig, L.S., and D. Summerbell 1985 Maps of strength of positional signalling activity in the developing chick wing bud. J. Embryol. Exp. Morphol., 87:163-174.

Iten, L.E. 1982 Pattern specification and pattern regulation in the embryonic chick limb bud. Am. Zool., 22:117-129.

Iten, L.E., and D.J. Murphy 1980 Pattern regulation in the embryonic chick limb: Supernumerary limb formation with anterior (nonZPA) limb bud tissue. Dev. Biol., 75:373-385.

Javois, L.C. 1984 Pattern specification in the developing chick limb. In: Pattern Formation: A Primer in Developmental Biology. G.M Malacinski and S.V. Bryant, eds. Macmillan, New York, pp. 537579.

LeDouarin, N. 1973 A biological cell labeling technique and its use in experimental embryology. Dev. Biol., 30:217-222.

MacCabe, B.A., M.T. Gasseling, and J.W. Saunders 1973 Spatiotemporal distribution of mechanisms that control outgrowth and an teroposterior polarization of the limb bud in the chick embryo. Mech. Ageing Dev., 2:1-12.

Saunders, J.W., and M.T. Gasseling 1963 Trans-filter propagation of apical ectoderm maintenance factor in the chick embryo wing bud. Dev, Biol., 7:64-78.

Saunders, J.W., and M.T. Gasseling 1968 Ectodermal-mesenchymal interactions in the origin of limb symmetry. In: Epithelial-Mesen chymal Interactions. R. Fleischmajer and R.E. Billingham, eds. Williams \& Wilkins, Baltimore, pp. 78-97.

Smith. J.C. 1979 Evidence for a positional memory in the development of the chick wing bud. J. Embryol, Exp. Morphol., 52:105-113.

Stocker, K.M., and B.M. Carlson 1988 Preservation of the ability of dissociated quail wing bud mesoderm to elicit a position-related differentiative response. Am. J. Anat., 182:84-95.

Summerbell, D. 1979 The zone of polarizing activity: Evidence for a role in normal chick limb morphogenesis. J. Embryol. Exp. Morphol., 50:217-233.

Summerbell, D., and L.S. Honig 1982 The control of pattern across the anteroposterior axis of the chick limb bud by a unique signalling region. Am. Zool., 22:105-116.

Summerbell, D., and C. Tickle 1977 Pattern formation along the anteroposterior axis of the chick limb bud. In: Vertebrate Limb and Somite Morphogenesis. D.A. Ede, J.R. Hinchliffe, and M. Balls, eds. Cambridge University Press, Cambridge, pp. 41-53.

Tickle, C., D. Summerbell, and L. Wolpert 1975 Positional signalling and specification of digits in chick limb morphogenesis. Nature (Lond), 254:199-202.

Wolpert, L. 1971 Positional information and pattern formation. Curr. Top. Devel. Biol., 6:183-224. 